\title{
Policies for promoting green buildings at the local level: a case study of Ningbo, China
}

\author{
W. Deng \& L. Tang \\ Department of Architecture and Built Environment, \\ University of Nottingham Ningbo China, China
}

\begin{abstract}
This paper is based on an ongoing research project funded by the World Bank GEF Program, which aims to identify the key policy incentives for promoting green buildings using a city in China as a case study. China is undergoing the largest scale of urbanization in history and at an unprecedented pace. The construction and operation of buildings have inevitably brought severe pressures on resource conservation and environmental protection. China has initiated policies, strategies and financial incentive schemes at a national level to address these issues. It is also seen that there is a growing interest in recent years at the local government level in promoting green buildings. Ambitious green building development targets have been proposed in some Chinese cities. This paper will take a look at the current national policies and targets and then discuss the motivations and opportunities of developing green buildings from a perspective of local governments. Questionnaire surveys and interviews have been conducted in the case study city of Ningbo, China. Based on these surveys and interviews, the key areas for policy improvement for the case study city have been identified.

Keywords: policy, green building, promotion, local government, Ningbo, China.
\end{abstract}

\section{Introduction}

China is undergoing the largest scale of urbanization in history and at an unprecedented pace. Between 1991 and 2012, China's urban population has increased from $26.4 \%$ to $52.6 \%$ in percentage terms. The urban built areas have expanded from 12,856 to 45,566 square kilometres over the same period, an increase of 3.5 times greater in about two decades (National Bureau of Statistics [1]). Enormous new buildings in cities have been constructed to accommodate the 
increased population. In recent years China has been adding about 1.7 billion square meters of new floor space on an annual basis (Li and Shui [2]). As estimated by the Building Energy Conservation Center (BECC) of Tsinghua University, the annual rate of new construction in China equals the total amount of new building in all developed countries (BECC [3]). In 2005 Shanghai alone added more space in the form of residential and commercial towers than exists in all of New York City (Fernandez [4]). Taking the annual addition to the residential building stock, the number has soared from 0.4 billion $\mathrm{m}^{2}$ to approximately 0.7 billion $\mathrm{m}^{2}$, a growth rate of $69 \%$ in the last 10 years (Li and Shui [2]).

Cities in general and the built environment in particular, during their life-cycle, have a significant environmental impact both at local and global levels. The rapid expansion of urbanization level has inevitably brought severe pressures on resource conservation and environmental protection in Chinese cities. The increasing pollution, traffic and energy consumption in the urban areas are becoming alerting matters in China. Moreover, given the long lifetime of buildings, choices made today on the construction of buildings will have long-term effects influencing the overall environmental performance of cities for decades to come (Ye et al. [5]).

Buildings have become a major energy consumer in China. Building operational consumption varies between $16 \%$ and $30 \%$ of the total national consumption owing to the research scope and different methods used (e.g. BECC [3], IEA [6], Yang and Kohler [7], He et al. [8]). If embodied energy used for manufacturing building materials is taken into account, the total building energy consumption may be around $40 \%$ of the national total ( $\mathrm{Li}$ and Jiang [9], cited in Yang and Kohler [7]). Though the current building energy consumption is already high, a further rapid growth is expected. BEEC has projected the national total building energy consumption by 2030 which was based on the trends of three variables, respectively, floor area per capita, life-style and technology evolution. The combined effects of these three factors would determine building operation consumption in 2030 varying from an increase of only $14 \%$ (the best scenario) to $270 \%$ (the worst scenario). This also implies there is huge potential to reduce energy use in building sector in China (BECC [3]).

Recognizing these resource and environmental challenges related to the construction and operation of buildings, and moreover, the significance of a broad concept of developing a "resource-conserving and environmental friendly society", China has initiated policies, strategies and pilot projects at both national and local levels to address these issues, with focuses on three aspects: a) low-carbon/green buildings; b) new urban areas; and c) retrofits for the existing contexts.

Incentivized by the policy mechanisms, there is a growing interest in promoting green buildings in Chinese cities in recent years. Currently there are 353 building projects certified by the Chinese Green Building Evaluation System (GBES) (Ye et al. [5]) and 195 projects by LEED certification (Green Building Map [10]), jumping from only 10 and 14 respectively in 2008. There are also around 280 Chinese cities that have declared an ambition to develop "eco-city" or "low carbon city" (China Society for Urban Studies [11]). Green building development is a core requirement for these eco-city projects. For example, Tianjin Eco-City, a joint 
project between China and Singapore, requires all buildings within the city must be certified by a green building rating system such as GBES, LEED and Green Mark. Such a city scale implementation has deeply shaped the local construction industry, from design, material manufacturing, construction to operational management, and green building sector has become a valuable contributor to the local economy.

This paper is based on an ongoing World Bank GEF funded project "Promoting Green Building Development in Ningbo China" (Ref Number 2-C-CS003), which aims to propose a policy framework for promoting green buildings in the selected case study city. The detailed policy suggestions are expected to be submitted to the local government at the end of 2015. This paper will focus on the identification of the key areas for policy improvement in Ningbo China.

\section{Policy overview for green building development in China}

The concept of green building was defined in the first edition of GBES in 2006. To be specific, a green building should be energy-saving, water-saving, materialsaving, land-saving and environment-benign, summarized as "four savings and one benign". Generally the Chinese legal and policy systems for developing green buildings comprise 4 levels (fig. 1). The Energy Conservation Law, Renewable Energy Law, Construction Law and Environmental Protection Law constitute the legal basis and give the general principles for developing green buildings. The State Council has issued regulations to enforce the laws and some provincial and local governments also have developed their own regulations for improving building environmental performance. Building design standards for various climatic zones have been issued by the Ministry of Housing and Urban-Rural Development (MoHURD). GBES is the first comprehensive system for whole building assessment and has been a national standard since then. Before GBES, there were fragmented assessments on various aspects of building environmental performance such as energy, material and water. Policy and financial incentive schemes have been proposed at both national and local levels. For example, in 2012, an incentive scheme has been proposed by MoHURD that buildings certified at GBES Three Star level will be subsidized with 80 RMB per square meter floor area, and $45 \mathrm{RMB}$ for 2 Star level projects.

Some local government have developed their own green building evaluation systems, which often have more rigid requirements on building environmental performance than national standards. For example, Beijing is executing the new goal of $75 \%$ building energy efficiency since 2011 (Li et al. [12]), compared to the national requirement of building energy saving of 50\%. Shanghai and Tianjin also require minimum $65 \%$ energy saving for new buildings.

It has been seen in recent years there is a growing interest in promoting building environmental performance at local government levels. Recently Beijing has announced that the municipal government would subsidize the energy efficiency retrofit of buildings, offering RMB 100 per square meter in addition to the subsidy 


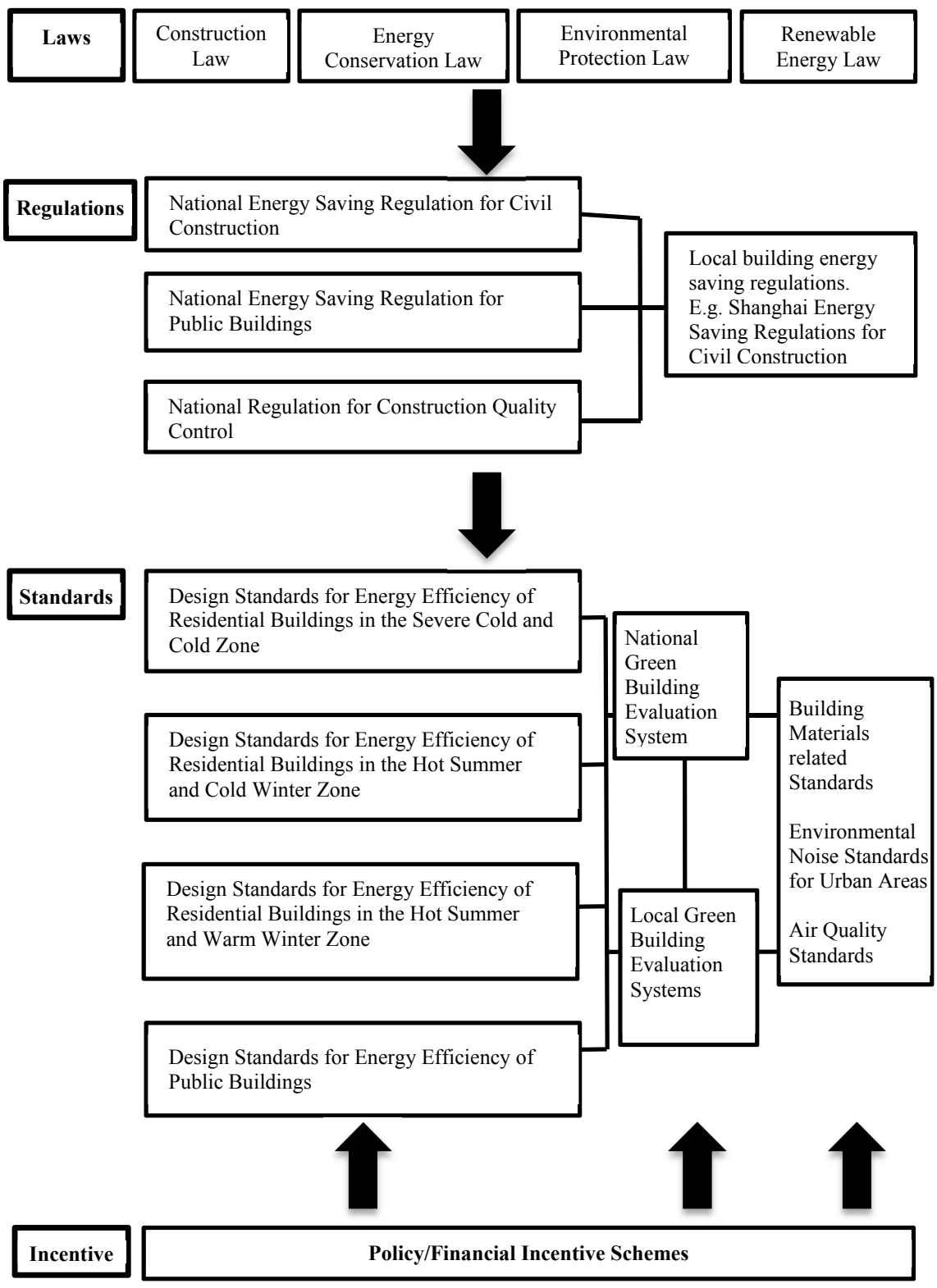

Figure 1: China's legal and policy systems for green building development.

from the central government, and would furthermore subsidize any retrofit which included the installation of solar water heating systems by up to RMB 200 per square meter ( $\mathrm{Li}$ and Shui [2]). The support of green building development from local governments is motivated by the following reasons: 
- To reduce energy consumption and related carbon emission. The National $12^{\text {th }}$ Five-Year Plan required $16 \%$ and $17 \%$ drop in energy consumption and $\mathrm{CO}_{2}$ emission per unit GDP. The $12^{\text {th }}$ Five-Year Special Program for Building Energy Conservation required a minimum energy consumption reduction of $10 \%$ for public buildings. Such national level overall targets have been broken down to provincial and city level. For example, the central government has allocated the energy saving per unit GDP targets to the provincial governments, with the highest reduction of $18 \%$ (e.g. Shanghai) and the lowest of $10 \%$ (e.g. Tibet) (The State Council [13]). These provincial level targets were further decomposed and re-allocated to city level governments. Local governments at city level have been under pressure to achieve such quantitative reduction targets.

- To reduce local environmental pollution. Many Chinese cities have been suffering from severe air pollution. As around $78 \%$ of the national total electricity is generated by coal burning, consuming energy has been a main reason for local air pollution. To tackle air pollution, local governments in China need to bring down energy consumption in buildings as it is a major consumer of energy.

- To create new business opportunities. The delivery of green buildings, from a view of the entire supply chain, involves many aspects such as planning, design, geological survey, construction, material manufacturing, and facility management. Liu et al. [14] estimate a potential market of green buildings in China would amount to 1.5 trillion RMB (US\$220 billion). This implies an attractive business opportunity for local governments.

\section{The context of Ningbo and survey analysis}

Ningbo, located at the eastern coast of China with a population of 5.77 million, has been selected as the case study city for this research. The city has an official energy saving target of $18.5 \%$ for the $12^{\text {th }}$ Five Year Plan period (2011-2015), which is higher than the national average of $16 \%$. Building energy saving is recognized by the city government as a focus area to achieve this target. Green building is still a new concept in Ningbo. Till the end of 2014, there are only 14 buildings certified by GBES or LEED. However the city government has issued three directives in 2014 to accelerate the development of green buildings in the city. The main points of the directives include:

- $\quad$ Set up a new Leading Group for Green Building Development chaired by a deputy mayor.

- All government funded construction must be certified by GBES.

- All commercial buildings with a construction area over 20,000 square meters must be certified by GBES.

- Over 10 million square meters green building will be construct by the end of 2015.

- Over 1 million square meters existing buildings will be retrofitted to achieve energy efficiency. 
- Commercial properties with green building certification are allowed to pre-sell depending on the level of the green certification assigned, for example, a certified three star commercial property can be pre-sold when the foundation is completed; a certified two star building can be placed in the market when minimum one fourth of the main structure is completed.

A robust and complete policy framework is needed to achieve the above targets. Supported by the city government, the project team has conducted a city-wide questionnaire survey to investigate perceptions from various practitioners in Ningbo on the driving and impeding factors for green building development. The main survey question areas are listed in table 1. A total of 87 effective responses were returned. The sample of respondents comprises 43 design firms, 26 construction contractors and 18 property developers. After the questionnaire survey, follow-up interviews with relevant senior managers from six major enterprises were carried out to further understand the current situation of green building development in Ningbo.

Table 1: The main survey question areas.

\begin{tabular}{|l|l|}
\hline Question areas & Examples \\
\hline $\begin{array}{l}\text { What industrial sectors are relevant to green } \\
\text { building development? }\end{array}$ & $\begin{array}{l}\text { Design, construction, material } \\
\text { manufacturing, etc. }\end{array}$ \\
\hline $\begin{array}{l}\text { To what extent are the current conditions } \\
\text { sufficient or insufficient for green building } \\
\text { development in Ningbo? }\end{array}$ & $\begin{array}{l}\text { Construction, design, training, } \\
\text { renewables, assessment, etc. }\end{array}$ \\
\hline $\begin{array}{l}\text { What are the most important features of green } \\
\text { building for property purchasers? }\end{array}$ & $\begin{array}{l}\text { Construction quality, comfort, energy } \\
\text { consumption, operational cost, etc. }\end{array}$ \\
\hline $\begin{array}{l}\text { What are the factors affecting green building } \\
\text { development in Ningbo? }\end{array}$ & $\begin{array}{l}\text { People's awareness, incentive } \\
\text { mechanism, costs, standard system, } \\
\text { knowledge, talent, etc. }\end{array}$ \\
\hline $\begin{array}{l}\text { What green building technologies are suitable } \\
\text { in Ningbo? }\end{array}$ & $\begin{array}{l}\text { Adjustable shading device, vertical } \\
\text { greening, renewables, use of } \\
\text { underground space, building energy } \\
\text { management, etc. }\end{array}$ \\
\hline $\begin{array}{l}\text { What suggestions are proposed for promoting } \\
\text { green buildings in Ningbo? }\end{array}$ & $\begin{array}{l}\text { Government policy, training, standards, } \\
\text { incentive mechanism, etc. }\end{array}$ \\
\hline
\end{tabular}

The survey indicates that the participants took a broad view on green building chain, which involves planning, designing, construction, manufacturing of building materials, provision of building service systems, green building consulting and evaluation, building operation and maintenance, reuse and recycling of wastes, pollution control, green building training, building IT systems and building demolishment. Among them, building design, construction, building materials and waste recycling and reuse are deemed to be the most relevant areas for green building development (fig. 2). 


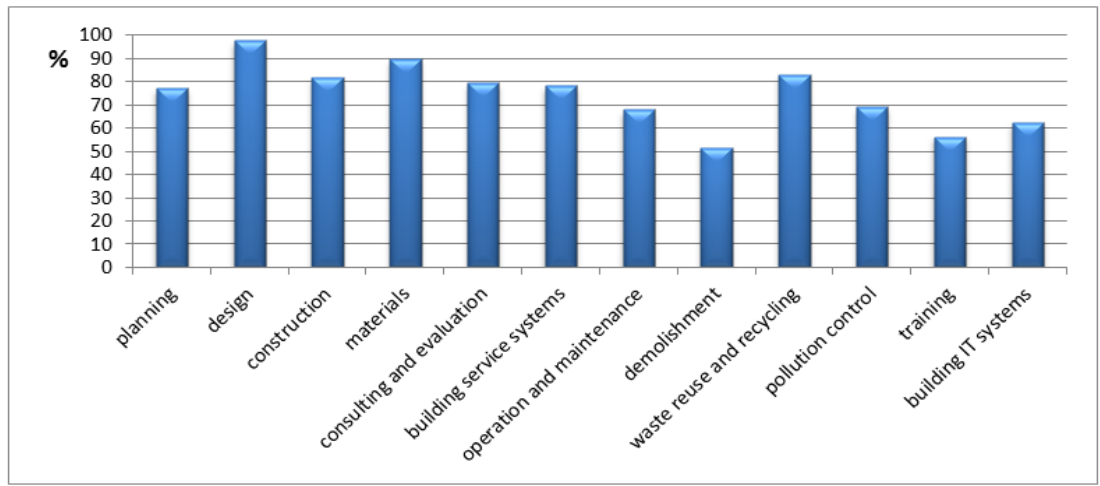

Figure 2: Participants' view on green building related areas.

The most important features of green building, from a purchaser's view, are increase of comfort, followed by reduction of operational cost and improvement of construction quality (fig. 3). Only 14\% of the participants thought energy and resource saving potential is appealing for property purchasers. The reasons behind might be attributed to the fact that the power cost in China is subsidized and does not reflect the real price.

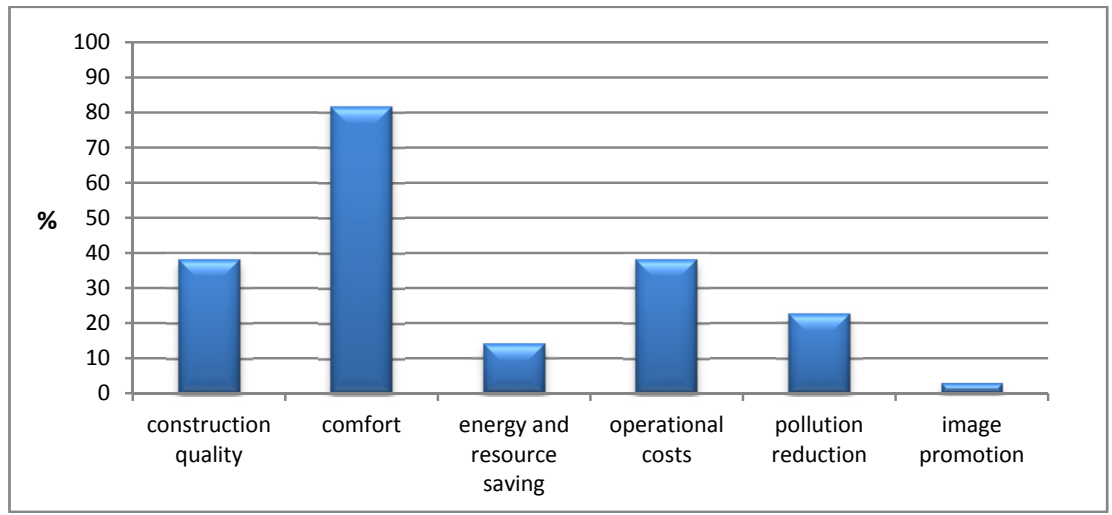

Figure 3: Participants' view on green building features.

A number of factors, which might affect green building development in Ningbo, were given in the questionnaire for evaluation. These factors comprise: a) lack of market recognition; b) high cost of green building products; c) incomplete industrial chain; d) inadequate incentive mechanism; e) lack of standard systems; f) no mandate requirement from government; g) lack of platforms to publicize and demo new technologies; h) lack of coordination between different stages of green building development; i) lack of industrialization of building products, e.g. prefabrication; j) lack of competitive building products and producers in 
Ningbo; k) lack of motivation from property developers; 1) inadequate access to relevant knowledge and technologies; m) lack of qualified professionals. Participants are required to use 3 scales to reflect their preferences. Fig. 4 indicates the top 5 issues that were deemed to be the most influential factors affecting the current green building development in Ningbo, which are inadequate market recognition, inadequate incentive mechanism, lack of platforms to publicize and demo new technologies, lack of coordination between different stages of green building development (e.g. design, construction and building operation), and lack of industrialization of building products.

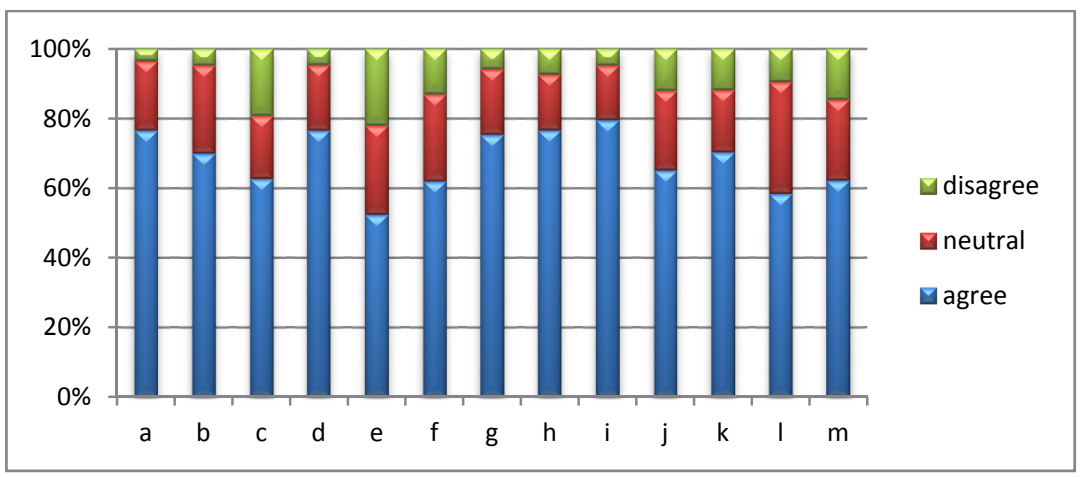

Figure 4: Participants' view on various factors affecting green building development in Ningbo.

The questionnaire lists a range of building environmental technologies (26 in total), and participants were required to select the most suitable ones for Ningbo. Addition of technologies was allowed if participants thought a technology was missing from the list. Eight technologies were picked out as the most suitable ones including permeable surface, wastes classification, energy saving design, thermal insulation, acoustics design, water saving, and diverted drainage system for sewage and rainwater. Seven technologies were thought less suitable for Ningbo, which are: material saving design, indoor thermal control, heat storage, rainwater recycling, reuse of old construction elements and IS014001 certification.

Suggestions for possible policy improvement from the participants were focused on proposing local incentive schemes, providing training, set up online platform for information exchange, encouraging the use of prefabricated building elements, developing a green building technologies and products list by the local government, and increasing public awareness.

\section{Discussions}

The survey has provided valuable insights and references for proposing policy suggestions for promoting green building development in Ningbo. The final report of policy suggestions is expected to be submitted to the city government later this year. Currently several areas for policy improvement are identified, which include: 
- Increase of public awareness and market recognition. The green building industry in Ningbo is emerging and immature. Property purchasers are not willing to buy green buildings at a higher cost. One important reason is the public is not familiar with the concept of green building and the potential financial return due to saving energy and water bills from a long term perspective. The local government should use mass media to publicize green building, and support mortgage institutions to lend to green building purchasers at a lower down payment and mortgage interest.

- Introduction of robust incentive schemes. Currently the increased cost is around $70 \mathrm{RMB}$ per square meter for a two star green building certified by GBES in Ningbo, and 140 RMB for a three star certified building. The national subsidies are 45 and 80 RMB separately for two star and three star buildings. A top-up around 15-25 RMB per square meter could be considered from the local government. Besides this, green building developers might be given more pricing power (housing prices must be examined by the local government).

- Better coordination between different stages of green building development. As reflected from the survey, inadequate coordination can severely weaken the effort for developing green buildings. Promoting general contracting might be future direction. This will allow a general contractor to organize and supervise a green building project from the beginning to the end. Also building information management (BIM) may serve as a life cycle data bone to allow information input and extracting at different stages of green building development.

- Establish a comprehensive online platform for policy updating, information exchange, and new technology promotion; set up a city-wide energy monitoring network for large-sized public and commercial buildings; set up a green building database which can provide evidence based information for future policy amendment.

\section{Conclusion}

This paper reports an ongoing research project regarding promoting green buildings at local government level in China. Chinese cities have been allocated quantitative targets for energy saving and carbon emissions. Green buildings are seen as a key area to achieve these targets. Surveys and interviews have been undertaken to investigate the local perceptions for green building development in the case study city- Ningbo. Several key areas for policy improvement, such as incentive mechanism and coordination of various stages of green building development, have been identified. A final report with detailed policy suggestions is expected to complete later this year.

\section{References}

[1] National Bureau of Statistics, China Statistical Yearbook 2013, China Statistics Press, 2014. 
[2] Li, J. \& Shui B., A comprehensive analysis of building energy efficiency policies in China: status quo and development perspective. Journal of Cleaner Production, Vol. 90, pp. 326-344, 2015.

[3] Building Energy Conservation Center (BECC), China Building Energy Conservation Annual Report, Tsinghua University, China Building Industry Press, 2009.

[4] Fernandez, J., Resource consumption of new urban construction in China. Journal of Industrial Ecology, Vol. 11, Issue 2, pp. 99-115, 2008.

[5] Ye, L., Cheng, Z., Wang, Q., Lin, W., Ren, F., Overview on green building label in China. Renewable Energy, 53, pp. 220-229, 2013.

[6] IEA, World Energy Outlook 2007, International Energy Agency, 2007.

[7] Yang, W. \& Kohler, N., Simulation of the evolution of the Chinese building and infrastructure stock. Building Research \& Information, Vol. 36(1), pp. 1-19, 2008.

[8] He, B.J., Yang, M., Ye, Mou B., Zhou, Y., Overview of rural building energy efficiency in China. Energy Policy, Vol. 69, pp. 385-396, 2014.

[9] Li, Z. \& Jiang, Y. (2006), Pondering over the situation of domestic generalized building energy consumption. Architectural Journal, Vol. 7, pp. 30-33, in Chinese.

[10] Green Building Map, http://www.gbmap.org:86/

[11] China Society for Urban Studies, China low carbon and ecological cities annual report 2012, China Building Industry Press, 2013.

[12] Li, Y., Yang, L., He, B., Zhao, D., Green building in China: needs great promotion. Sustainable Cities and Society, Vol. 11, pp. 1-6, 2014.

[13] The State Council 2011, http://www.gov.cn/gongbao/content/2011

[14] Liu, J.Y., Low, S.P., He, Green practices in the Chinese building industry: drivers and impediments. Journal of Technology Management in China, Vol. 7, No. 1, pp. 50-63, 2012. 